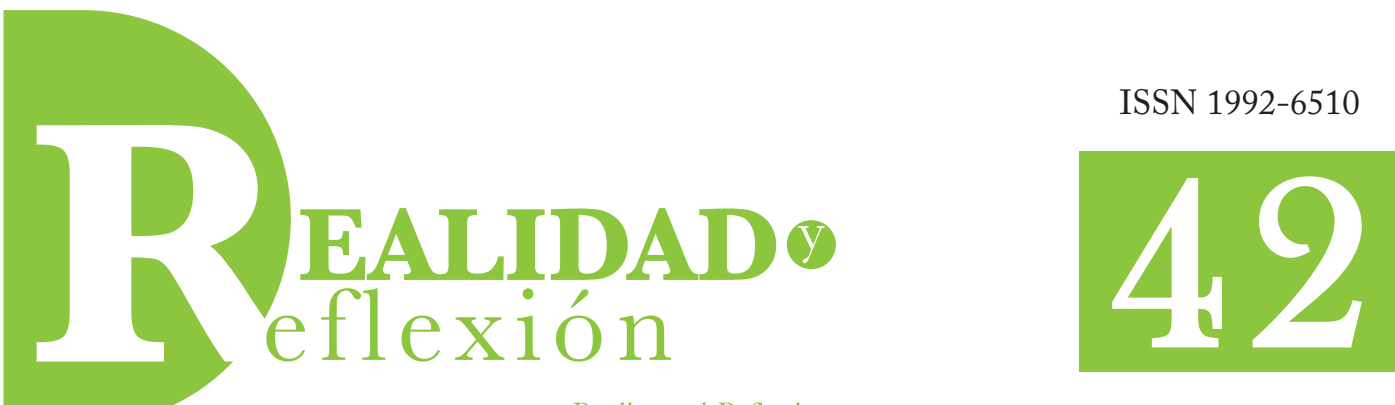

Reality and Reflection

Año 15, N 42, San Salvador, El Salvador, Centroamérica. Revista Semestral Julio-Diciembre 2015

Year 15, N 42, SAN Salvador, El SALVAdor, Central America. Semestral Journal July-December 2015

\title{
Matices cronológicos de la violencia escolar en E1 Salvador \\ (Apuntes críticos para la comprensión del fenómeno)
}

\author{
Chronological aspects of school violence in El Salvador \\ (Critical notes for understanding the phenomenon)
}

Herberth Alexander Oliva Bachelor of Education. Southern Texas University. Maestro en Administración de la Educación, Universidad Pedagógica de El Salvador. Posgrado en Pedagogía de la Violencia Escolar. Tel Aviv University. Investigador para el área educativa, ICTI-UFC holiva@ufg.edu.sv

\section{RESUMEN}

Matices cronológicos de la violencia escolar en El Salvador, es un artículo de connotación académica que pretende plasmar una concepción cronológica y epistemológica del surgimiento de la violencia escolar y su evolución hasta convertirse en criminalidad escolar, recogiendo además las diversas experiencias que el sistema educativo salvadoreño ha llevado a cabo como parte del abordaje y seguimiento a dicho fenómeno.

Palabras clave: Violencia escolar, historia, estudiantes, sistema educativo.

\section{ABSTRACT}

Chronological aspects of school violence in El Salvador, it is an article of academic connotation that tries to form a chronological and epistemological conception of the emergence of the school violence and its evolution, up to turning into school criminality, gathering in addition the diverse experiences that the educational salvadoran system has carried out as part of the approach and monitoring the phenomenon.

Keywords: School violence, history, students, educational system. 


\section{Introducción}

El procesamiento hermenéutico sobre la comprensión e interpretación de la historia de la escuela en El Salvador se origina durante el siglo 19, tiempo en el cual se estipula de forma categórica el establecimiento de las normas y los procesos que regirían el sistema educativo salvadoreño. Desde los tiempos del Gobierno del Capitán General Gerardo Barrios, pasando por la Reforma Educativa del ministro Béneke en 1968, hasta llegar al posmodernismo pedagógico del siglo XXI, la caracterización del problema de la violencia escolar en el contexto educativo salvadoreño, ha permitido la creación de un marco de interpretación en el cual la sociedad puede percatarse, que el enigma de la violencia escolar, ha estado presente desde los inicios formales del sistema educativo. Ello ha caracterizado que la violencia escolar se transforme en un fenómeno de grandes dimensiones y de diversas reacciones, las cuales son el parámetro de referencia para entender la ola de violencia y criminalidad que afecta el interior de la escuela salvadoreña.

El presente artículo de análisis permite concretizar, en una reflexión clara y precisa, la interpretación epistemológica de la violencia escolar, partiendo de la idea de que la violencia escolar se genera como un fenómeno educativo derivado de los procesos de interacción escolar, a través de sentimientos, actitudes, malos hábitos de convivencia y comportamientos inmorales entre agresores y agredidos. Para fines de estructuración el artículo se organiza en la siguiente forma:

- Comprendiendo el fenómeno sociohistórico de la violencia escolar salvadoreña.
- Causas, razones y justificaciones de la violencia escolar, como problemática de la escuela a tiempo pleno.

- Análisis e interpretación sociológica y psicológica de la violencia escolar.

- Problematización de la violencia en el contexto socioeconómico salvadoreño.

El punto de análisis del que se inicia la concreción de una visión epistemológica en el abordaje de la violencia escolar salvadoreña, es el poder recurrir a la ciencia del conocimiento para entender en mejor forma el fenómeno de estudio, así como las circunstancias históricas, psicológicas y sociológicas que llevan a la obtención del marco de referencia que valida el respectivo análisis derivado.

\section{Comprendiendo el fenómeno sociohistórico de la violencia escolar salvadoreña}

Una forma de interpretar el fenómeno de convivencia social, denominado violencia escolar, es percibir su comprensión como un avasallamiento psicológico o físico reiterado, de una persona con menos poder o autoridad por parte de una persona o grupo de personas con mayor poder o autoridad.

Sobrelabase de una aproximación epistemológica, el termino violencia, proviene del latín violentǐa. Significa "cualidad de violento, acción y efecto de violentar o violentarse, acción que atenta contra el natural modo de proceder".

Hablar del término escolar, es hacer referencia a que dicho concepto proviene del latín scholāris, 
definiéndolo entre otras acepciones como "perteneciente o relativo al estudiante o a la escuela"; "estudiante que asiste a la escuela para recibir la enseñanza obligatoria”.

Por lo tanto, una acción de violencia escolar se materializa como una agresión metódica y sistemática que puede darse a nivel físico y psicológico como insultos, burlas, motes, en lo verbal. Y en lo no verbal, con gestos groseros, desprecio, ignorancia, aislar a la víctima, enviar notas ofensivas, etc. A modo de argumento concluyente se dice que la violencia contempla los actos que se ejercen con la intención de lograr la concreción de una acción a través del uso de la fuerza, haciendo hincapié en una conducta violenta, que busca dañar física o mentalmente a otra persona mediante el sometimiento.

La presencia preocupante de la violencia, en gran parte de los espacios sociales de la vida cotidiana de El Salvador, ha suscitado opiniones de algunos especialistas en el tema de violencia escolar en América Latina, por ejemplo que "el fenómeno de la violencia y de la violencia escolar en particular ha alcanzado el reconocimiento de enfermedad social que afecta en gran magnitud, y que los propios contextos familiares y sociales, así como la ausencia de políticas públicas la han favorecido, permitiendo que su crecimiento (el de la violencia escolar) continúe asfixiando el tejido social". ${ }^{1}$ Esto permite acotar que la violencia escolar es generada por muchos factores que de una u otra manera se han filtrado en los elementos sociales que configuran la

1 CASTRO SANTANDER, Alejandro. "Violencia silenciosa en la escuela. Dinámica del acoso escolar". Buenos Aires: Editorial Bonum, 2007. cotidianidad educativa salvadoreña; dentro de estos elementos se pueden nombrar los medios de comunicación, videojuegos, publicidad agresiva o manifestaciones violentas de convivencia social, entre otros.

Cabe destacar que los factores posibles, según la naturaleza social y antropológica de convivencia escolar que dan cabida a este mal endémico (violencia escolar), son delincuencia, drogadicción, violaciones, homicidios, hogares desintegrados y la influencia de los entornos de convivencia, por mencionar algunos.

En ese mismo orden de ideas, lo expuesto en las referencias anteriores permite reafirmar la magnitud de la violencia en los diferentes espacios de la sociedad actual y la necesidad de llevar a cabo un proceso educativo centrado en la formación de valores que, desde las primeras edades, favorezca el desarrollo de conductas positivas y la conformación de actitudes y prácticas en las que prevalezcan el diálogo, la interacción pacífica y la tolerancia como formas permanentes de relación, que deriven en futuros adultos con una sólida formación en valores, que sean capaces de transformar en un mundo solidario y en paz la realidad que en un futuro vivirán.

\section{Marco histórico de la violencia escolar en El Salvador}

La concreción de la existencia histórica de la violencia en el contexto social salvadoreño es tan antigua como la historia de la conquista y la colonización de la región cuscatleca; sin embargo, la violencia escolar ha estado presente en casi todos los contextos de interacción social de la escuela, por lo que también es necesario 
aclarar que la violencia no debe asimilarse como un fenómeno natural y cotidiano que debe suscitarse en todo espacio educativo.

Para el especialista en el tema de violencia juvenil, el abogado Héctor Ramón Flores Chavarría, de la Corte Suprema de Justicia, la construcción de un precepto histórico sobre el origen de la violencia escolar da paso, en entrevista realizada, a la siguiente interpretación:

Una posible aproximación al origen de la violencia escolar en el plano salvadoreño, se desarrolla en la década de los años 70's, durante el transcurso de los Juegos Estudiantiles, en donde dichos espacios de convivencia deportiva, facilitaron al calor de la rivalidad y competitividad del juego, el aparecimiento de rencillas y conflictos entre los estudiantes de los colegios participantes de estas actividades. Por lo general eran jóvenes de clase media, quienes vieron en este tipo de violencia, un sentido de pertinencia institucional educativa, lo cual facilitó una búsqueda de identidad por parte de los jóvenes, mediante la ejecución de actos violentos. La problemática que generaban estos primeros momentos históricos de la violencia escolar, no abarcaba la dimensión conflictiva de estos tiempos, llegándose a denominar a estos conatos de violencia como cosas de jóvenes', buscando apaciguar la situación debido a que dicha violencia escolar se suscitaba exclusivamente entre instituciones educativas privadas de mayor prestigio académico y económico del país.

Para el jurista antes mencionado los pilares que fundamentan la historia de la violencia escolar salvadoreña están estructurados en los modos y medios de convivencia que ponían de manifiesto un supuesto espíritu competitivo de la juventud de aquel entonces, por denotar cuál institución educativa era mejor que la otra; sin embargo, también señala que con el devenir del tiempo, los contextos de la violencia escolar fueron sobrepasados hasta llegar a una particularidad en la que entran los institutos del sistema educativo público. Para el caso también argumenta lo siguiente: "No obstante que fueron estudiantes de clase media quienes dan una posible apertura de interpretación y surgimiento histórico de la violencia escolar en el país, también se fue creando en los centros educativos públicos una segmentación entre Institutos Técnicos e Institutos Nacionales".

A partir de lo señalado por el licenciado Flores Chavarría, se procedió a la realización de una exhaustiva investigación bibliográfica que permitiera conocer más sobre el origen de la historia de la violencia escolar salvadoreña, y se encontró una importante nota periodística de Fernando Romero, quien argumenta lo siguiente:

Las escenas violentas que protagonizan estudiantes de varios centros educativos en la actualidad, conocidas de forma popular como las riñas estudiantiles, que muchas veces tienen como destino la cárcel, el hospital o la morgue, tienen su origen en las confrontaciones entre las barras de los equipos colegiales de baloncesto de bace más de 70 años.

En ese entonces, según el estudio de la Facultad Latinoamericana de Ciencias Sociales (FLACSO) "Compitiendo en bravuras. Violencia estudiantil en el Área Metropolitana de San Salvador", estudiantes de colegios privados, como 
el Externado San José, el Liceo Salvadoreño, el Colegio García Flamenco y el Instituto El Salvador, que apoyaban a sus equipos colegiales, eran partícipes de las riñas cuando no se conformaban con las decisiones de los árbitros, cuando sus equipos perdían o, simplemente, por hacer el juego de 'molestar' a sus rivales.

En 1946, el periódico LA PRENSA GRÁFICA informó de la primera noticia sobre esas confrontaciones. "Desde ese momento, se reprochó desde distintas palestras la conducta impropia de los estudiantes. Fue en junio de 1959 cuando el 'leve' fenómeno de las confrontaciones entre las barras estudiantiles de los colegios privados tomó dimensiones mucho más violentas. La portada de este periódico del 17 de junio informaba sobre un tiroteo contra un autobús de la barra del Externado San José por parte de alumnos del Instituto El Salvador, luego de un juego de baloncesto en que el equipo del instituto perdió y fue entonces cuando la policía empezó a intervenir”. ${ }^{2}$

\subsection{Protagonistas históricos de la violencia escolar salvadoreña}

Con el ánimo de profundizar la caracterización histórica de la violencia escolar en el país, es necesario remontarse al análisis histórico del contexto sociopolítico de 1932, en donde como producto de la crisis mundial hubo un violento levantamiento armado del sector indígena, siendo controlado o rechazado con muerte y derramamiento de sangre. Bajo el mismo

2 ROMERO, Fernando, "El origen de los encuentros violentos entre los estudiantes” (en línea) edición digital La Prensa Gráfica, 17 mayo 2010, (fecha de consulta: 1 septiembre de 2014) disponible en: http:// www.laprensagrafica.com/el-salvador/social/118165-el-origendelos-encuentros-violentos-entre-los-estudiantes.html argumento de análisis histórico, el país atravesó una cruel guerra en la década de los años 60 con la nación hermana de Honduras; durante este conflicto se suscitó una cruel barbarie de asesinatos de ciudadanos salvadoreños expulsados del país hermano, dando lugar a una de las peores experiencias violentas jamás experimentadas a esa fecha. Otro acontecimiento fue el desarrollo del conflicto armado durante los años 80, conflicto que confrontó a grupos alzados en armas y fuerzas del Gobierno; ésta guerra se considera como la verdadera raíz de la violencia actual en el país, ya que no se puede pasar por alto la experiencia de una guerra como mecanismo para solucionar conflictos que marcan de por vida a las personas que la sufren.

Al finalizar el conflicto armado en El Salvador, surge con más fuerza y preponderancia el fenómeno de la violencia juvenil como una reacción inmediata al ambiente que antes existía en el interior del país, lógicamente al estar sometidos por años a las condiciones de violencia como una forma de vida y método de solución de conflictos dentro de las sociedad; para el caso, el reclutamiento de jóvenes por la Fuerza Armada y el reclutamiento de jóvenes por los grupos insurgentes alzados en armas.

Durante los años sesenta y setenta las riñas estudiantiles, cuyas causas para los jóvenes estaban en la rivalidad deportiva dentro de los campeonatos que jugaban sus equipos colegiales, dejaron de ser casos aislados y pasaron a ser un patrón de los juegos, en los que la Policía tenía un papel disuasivo.

Los colegios, de forma paulatina, desaparecieron de los escenarios violentos, y en 1978 el Externado 
San José se retiró de los campeonatos colegiales. Sin embargo, en ese mismo período de finales de los años setenta, institutos públicos como el INFRAMEN, el ITI (desde 1999, INTI) y la ENCO (hoy INCO) surgieron como herederos de la violencia entre instituciones.

E1 estudio de FLACSO, cuya última edición es de 2007 y en el que se contó con la colaboración de la Cooperación Técnica Alemana (GTZ), el Ministerio de Educación (MINED), la Secretaría de la Juventud, el Fondo de Naciones Unidas para la Infancia (UNICEF) y la ICCO de los Países Bajos, detalla que el 15 de mayo de 1982, durante la inauguración de los XXI Juegos Deportivos Estudiantiles, es la fecha del mítico origen de las rivalidades y confrontaciones actuales, cuando varios estudiantes del INFRAMEN y del ITI se enfrentaron con cinchos y botellas, después de lanzar objetos a los atletas del instituto adversario.

LA PRENSA GRÁFICA reportó también ese hecho violento que ocurrió en el estadio Flor Blanca, en el que resultaron dos estudiantes heridos, argumentando que desde un principio la barra del Instituto Técnico Industrial fue la provocadora del incidente, al lanzar objetos a los atletas del Nacional, cuando éstos hicieron su aparición en el desfile. Posteriormente, los del Nacional hicieron lo mismo al pasar los atletas del Técnico Industrial (...). Fue allí donde se dieron de hebillazos con la barra contraria.

Nota del editor

INFRAMOR: Instituto Nacional General Francisco Morazán ITI: Instituto Técnico Industrial

INTI: Instituto Nacional Técnico Industrial

ENCO: Escuela Nacional de Comercio

INCO: Instituto Nacional de Comercio
En el estudio antes mencionado de FLACSO se determinó que: Cuando los estudiantes y ex estudiantes cuentan los orígenes de las rivalidades actuales, muchas veces hacen referencia a incidentes que varían en múltiples aspectos. Sin embargo, lo que sobresale y queda constante es el hecho de que las mascotas, y en consecuencia el orgullo y la identidad del ITI e INFRAMEN, fueron objeto de humillación por los contrarios. Más allá de cualquier lesión física, son exactamente las lesiones a la identidad de la institución lo que resulta más difícil de sanar, dice el estudio.

Para el desarrollo del análisis etnográfico sobre el cual se sustenta la cosmovisión de la violencia escolar salvadoreña, se consultó al connotado pedagogo uruguayo radicado en El Salvador, el Dr. Óscar Picardo Joao, a quien al cuestionarle sobre el tema, puntualizo lo siguiente:

La Revista ECA No 547-548 de mayo-junio de 1994, de la Universidad Centroamericana José Simeón Cañas (UCA), presentó en esta edición un número monográfico titulado " $\mathrm{La}$ educación en El Salvador". Eran los albores de la reforma educativa en marcha, en donde la UCA junto a FEPADE y el Instituto para el Desarrollo Internacional de la Universidad de Harvard llevaban a cabo un profundo diagnóstico coordinado por Fernando Reimers. En esta revista aparecen dos artículos que permiten interpretar el origen de la violencia en los institutos nacionales: "La educación media en El Salvador" de José Luis Guzmán y Leonor Cariola, y "Problemas y perspectivas de las universidades privadas en El Salvador" de Joaquín Samayoa. 
El artículo de Guzmán y Cariola señala que después de la reforma desarrollista de 1968 (Béneke) la matrícula absoluta en educación media aumentó de 15,367 en 1965 a poco más de 100,000 estudiantes en 1992 (608\% de crecimiento). Por su parte, Samayoa anota que entre 1979 y 1991 el gasto público en el área social se redujo entre $52 \%$ y $55 \%$; presenta además los graves problemas de calidad en el nivel superior y finalmente anota otros datos de matrícula: para 1957, la población universitaria era de 1,648 estudiantes y el número de bachilleres graduados fue de 508 estudiantes, pero en 1970 la matrícula de educación superior ya era de 26,191 estudiantes y en 1991 asciende a 81,773 . Finalmente, Samayoa señala que "a comienzos de la década del sesenta, el número de estudiantes que egresaban de la educación secundaria, apto para ingresar a la universidad, había aumentado en forma considerable". Esto confirma el dato de Guzmán y Cariola."”

Bajo el análisis del argumento emitido por el Dr. Picardo se concluye que en tiempos de convulsión políticaydemigración del talento humano,segeneró un aumento de la matrícula de manera significativa, hubo además mayor deterioro de la calidad de la formación docente y menos presupuesto educativo, generando con ello las condiciones propicias para la generación de violencia escolar. Mientras las aulas de los institutos nacionales desde los años setenta comienzan exponencialmente a saturarse $y$ bacinarse con grupos de 50 y 60 estudiantes, de modo inversamente proporcional, la calidad pedagógica, eficiencia y liderazgo de directores y docentes disminuye; no debemos señalar con simpleza que lo que sucede en los

3 PICARDO JOAO, Oscar Carlos, "¿Violencia en los institutos nacionales?” (en línea) Edición digital La Prensa Gráfica, 30 marzo 2010, (fecha de consulta: 25 septiembre de 2014) disponible en: http:// www.laprensagrafica.com/opinion/editorial/104475-iviolencia-enlos-institutos-nacionales institutos nacionales es una "causa" o producto" de una sociedad violenta (esto es en "parte" cierto), ya que lo que sucede en estas instituciones es un fenómeno focalizado y con identidad propia que no se da en otros ambientes $u$ organizaciones similares. Lo que se da en los institutos es un problema de ingobernabilidad educativa por saturación de demanda y poca calidad en la oferta, y una de las manifestaciones de esto es la violencia. ${ }^{4}$

\subsection{Marco de referencia de la violencia escolar salvadoreña}

La violencia escolar vista desde un enfoque histórico no tiene data reciente; sin embargo, la escalada de esta, dentro del recinto escolar salvadoreño, ha provocado que las autoridades del Ministerio de Educación de El Salvador (MINED) busquen realizar acciones concretas enfocadas a prevenir la violencia y fomentar mejores formas de convivencia escolar. Algunos indicios de intervención institucional por parte de las autoridades educativas del país se evidencian en la Memoria de Labores MINED 2004-2005 Capítulo Gestión Educativa e Institucional, cuando el apartado 3.13 habla sobre el Convenio de Seguridad MINED-PNC: En dicho convenio se desarrollaron acciones y esfuerzos articulados de prevención y atención integral que buscaban reducir los factores de riesgo y fortalecer la protección en los ámbitos familiar, escolar y comunitario con el propósito de garantizar la seguridad de estudiantes. Todas las acciones antes mencionadas respondian al plan interinstitucional entre MINED-Gobierno y $P N C$ para el establecimiento de las relaciones entre el proyecto y el Plan de Gobierno País Seguro. ${ }^{5}$

4 Ibíd.

5 MINED, "Memoria de labores Ministerio de Educación de E1 Salvador 2004-2005”, pág. 41. 
Las propias autoridades gubernamentales en el ramo educativo señalaban que dentro de los principales logros alcanzados durante los años 2004-2005 en el marco de la gestión educativa e institucional estaban los siguientes:

1. Apoyar a los estudiantes mediante la implementación de 60 programas de intervención y manejo de la violencia estudiantil.

\section{Implementación de programas de} intervención en crisis, resolución de conflictos y disminución en el consumo de drogas en 50 centros de educación básica y 5 instituciones de educación media.

Para efectos de la presente investigación es válido señalar que desde el año 2004, bajo la administración de Darlyn Meza como ministra de educación, se hablaba de la puesta en marcha de un plan de seguridad escolar denominado Plan Escuela Segura, el cual tenía un componente de vigilancia en el entorno de los centros educativos. En nota periodística de 9 de julio del año 2004 se señalaba lo siguiente:

Las autoridades de Educación se mostraron ayer desconcertadas, pero decididas a tomar acción ante la cadena de actos violentos que, en menos de una semana, se han sucedido contra estudiantes del Instituto Nacional Francisco Menéndez (Inframen) y de dos colegios capitalinos con saldo de dos muertos y varios heridos. En un inicio, la PNC separa los hechos de lo que denomina violencia escolar. ${ }^{6}$

6 JOMA, Susana, Revisan "Escuela Segura" (en línea) Edición digital El Diario de Hoy, 9 julio 2004, (fecha de consulta: 7 de julio de 2015) disponible en: http://www.elsalvador.com/noticias/2004/07/09/ nacional/nac2.asp
La noticia de queuno delos principales rotativos del país hacía mención de que el 8 de julio de 2004 la entonces titular del ramo (MINED), la ministra Darlyn Meza y el subdirector general de la PNC, el subcomisionado Pedro González, sostuvieron un encuentro en donde se intercambió información que permitiera a ambas instituciones esclarecer si los hechos de violencia entre grupos estudiantiles son un fenómeno aislado o forman parte de una estructura delincuencial. El encuentro además sirvió para que el representante del ente policial expusiera a la ministra de educación, los diversos programas que la institución desarrollaba con la sana intención de prevenir que los estudiantes participaran en este tipo de riñas callejeras. Entre ellos estaba desde ese entonces el Plan Escuela Segura, el cual contaba con un componente de vigilancia a los entornos de los centros educativos; dicho plan fue bien recibido por la ministra al grado de que se comprometió a formular sugerencias para enriquecerlo y mejorarlo. La interpretación de la nota periodística plantea la idea de que es precisamente la Policía Nacional Civil la autora del Plan Escuela Segura, por lo que asume la iniciativa de mejorar las condiciones de seguridad de las instituciones educativas como una alternativa viable ante los constantes hechos de agresiones entre educandos.

El constante conflicto entre rivalidades estudiantiles motivó a que en el año 2004 el Secretario de Juventud, César Funes, propusiera la creación de una delegación de la PNC que velara por la seguridad de los estudiantes en los recintos escolares, todo ello con el fin de poner freno a los hechos de violencia; al respecto una nota periodista señalaba lo siguiente: 
En una entrevista sostenida con la comunidad del Instituto Nacional Francisco Menéndez, como parte de una gira por las instituciones educativas afectadas por el fenómeno de la violencia escolar, el funcionario planteó la idea de que la corporación policial capacite a un grupo de agentes para que se encarguen de velar por la seguridad de los alumnos de los centros donde se imparte educación media. ${ }^{7}$

La idea que exteriorizaba el funcionario gubernamental era que los miembros de la corporación policial pertenecientes a dicha unidad especial pudieran tener contacto permanente con los estudiantes con el ánimo de generar la suficiente confianza para reportar los intentos de violencia y denunciar a los presuntos responsables. En dicha noticia, vuelve a aparecer la confirmación que el Plan Escuela Segura fue una creación de la PNC. Al respecto la nota antes mencionada señalaba: "Por su parte, el viceministro de Educación, Jorge A. Muñoz, reconoció los esfuerzos que la PNC realizaba a través del Programa Escuela Segura y como parte de ello los patrullajes preventivos cerca de las instituciones". ${ }^{8}$

Entre los años 2005 y 2007 el Gobierno de El Salvador instauró un plan de políticas educativas en el que se priorizaban las necesidades que el país debería de cubrir desde el año 2005 hasta el 2021. Dicho plan se denominó Plan 2021, el cual ya daba las primeras señales a inicios del pleno siglo XXI de la urgente necesidad de darle un abordaje al

\footnotetext{
7 BURGOS Ana / JOMA, Susana, "Proponen policía especial para la violencia escolar” (en línea) Edición digital El Diario de Hoy, 7 julio 2004, (fecha de consulta 8 julio 2015) disponible: http://www. elsalvador.com/noticias/2004/07/07/nacional/nac3.asp\#

8 Ibíd.
}

problema de la violencia en el interior y el exterior de los centros educativos. El Plan 2021 promovía acciones de convivencia escolar que tenía entre sus prioridades educativas el lema "educar para el país que queremos". En dicho lema se señalaba "la necesidad de tener un país centrado en su gente, un país productivo, competitivo y democrático, con seguridad y equidad social que se desarrolla de manera sostenible y consolida su identidad" Uno de los objetivos primordiales del Plan 2021 era la formación integral de las personas; y de manera más puntual, en lo referido al tema de violencia escolar, la línea estratégica 2 enfatizaba la imperante necesidad de implementar en las escuelas un clima institucional positivo. Todo ello se desarrollaba mediante el programa complementario denominado Programa de prevención juvenil para la mejora del clima institucional (PODER), el cual fue un programa extracurricular dirigido a jóvenes entre los 13 y 21 años que se encontraban en los niveles de tercer ciclo y bachillerato, buscando que los estudiantes pudiesen cultivar habilidades positivas a fin de obtener libertad y capacidad reflexiva de tomar decisiones responsables (Ver Cuadro 1). El programa además buscaba evitar conductas negativas en los estudiantes jóvenes y pretendía despertar en ellos una conciencia reflexiva sobre lo importante de los procesos de sana convivencia en el interior de los centros educativos. El programa complementario del Pan 2021 promovía ambientes escolares y de convivencia seguros, que favorecieran los aprendizajes de los estudiantes, especialmente de aquellos que se desempeñaban en ambientes de mayor riesgo social.

9 MINED, "Memoria de labores Ministerio de Educación de El Salvador 2006-2007”. Pág. 14. 


\section{Cuadro 1}

Componentes y lineas de acción del programa PODER

\begin{tabular}{|c|c|}
\hline Componentes & Lineas de acción \\
\hline \multirow{3}{*}{ Educación para la vida } & Educación integral de la sexualidad \\
\hline & Desarrollo de contenidos con perspectiva de género \\
\hline & Prevención del consumo de drogas \\
\hline \multirow{3}{*}{ Promoción y desarrollo integral } & Recreación y deporte \\
\hline & Educación para el trabajo \\
\hline & Certámenes académicos y festivales artísticos \\
\hline \multirow{3}{*}{ Solidarida y convivencia escolar } & Solución creativa de conflictos \\
\hline & Mediación escolar \\
\hline & Promotores de Paz \\
\hline $\begin{array}{l}\text { Estrategias metodológicas } \\
\text { Proyectos concursables } \\
\text { Campamentos } \\
\text { Brigadas estudiantiles de solidaridad } \\
\text { Escuelas efectivas y solidarias }\end{array}$ & $\begin{array}{l}\text { Materiales didácticos utilizados: } \\
\text { Módulos de mediación escolar, Guías metodológicas para } \\
\text { mediación escolar, Juego para evaluar la mediación escolar, } \\
\text { Módulo formación promotores de paz, Paso a Paso para } \\
\text { elaborar los manuales de convivencia,Manual de participación } \\
\text { estudiantil, Guía del docente sobre educación para la vida } \\
\text { (Módulo 1: Adolescencia; módulo 2: Sexualidad; módulo } \\
\text { 3: Salud sexual y reproductiva), Manual de asertividad, } \\
\text { Manual sobre la prevención del uso indebido de drogas, } \\
\text { Juego educativo sobre asertividad "Así soy", Juego didáctico } \\
\text { para evaluación de "Mi proyecto de vida"; Juego didáctico } \\
\text { "Conócete amigo", Guía técnica de orientaciones para } \\
\text { prevención y atención del abuso sexual en centros escolares, } \\
\text { Guía técnica de orientaciones para la atención educativa de } \\
\text { las embarazadas en los centros escolares. }\end{array}$ \\
\hline
\end{tabular}

Fuente: MINED, “Memoria de labores Ministerio de Educación de El Salvador 2006-2007”. Pág. 30.

Bajo la lógica argumental del problema de la violencia escolar, el año 2007 fue denominado por iniciativa del Presidente de la República, Antonio Elías Saca, y por acuerdo legislativo, como año de la Convivencia y Paz Social. Por ello, el MINED desarrolló junto con otras instancias públicas y bajo coordinación del Ministerio de Seguridad y Justicia, la iniciativa "Escuelas por la Paz", que se focalizó en 12 centros escolares ubicados en tres zonas con alto índice de riesgo social: Altavista, IVU Montserrat y Lourdes Colón. Esta se desarrolló como parte del programa PODER, en consistencia con las áreas de acción y los componentes que dieron lugar a la elaboración de planes de trabajo en cada una de las escuelas involucradas. La continuidad de la actividad 
antes mencionada facilitó que las autoridades del ramo educativo del país crearan el programa denominado Atención a la juventud: Prevención de la violencia. De dicho programa se derivó la estrategia de Gestión integral ciudadana, la cual hizo énfasis en fomentar el respeto a los derechos humanos y a la implementación en el diario vivir de los estudiantes, de una cultura de paz, mediante la participación activa de convenios con organizaciones no gubernamentales, Policía Nacional Civil e iglesias.

A modo de argumento concluyente se puede señalar que el impacto del programa llevado a cabo por el MINED dio cobertura a un total de 1,259 centros educativos y 112, 450 estudiantes, los cuales se vieron fortalecidos en áreas como resolución de conflictos, convivencia escolar, gobiernos estudiantiles y fortalecimiento en valores entre los más destacados.

\section{E1 Sistema de Monitoreo de Violencia Escolar MINED; un primer acercamiento institucional al fenómeno}

El Sistema de Monitoreo de Violencia Escolar (SMVE) del MINED, surgió como una herramienta teórica que aportaba al cuerpo docente una serie de elementos metodológicos y conceptuales queles permitieran medircuantitativa y cualitativamente los niveles de violencia escolar en el sistema educativo salvadoreño, buscando crear acciones de prevención que lograran reducir en forma considerable la agresión mostrada en los diversos procesos de convivencia entre educandos y educadores (Ver Figura 1).

ElSMVE se derivó de los componentes y líneas de acción del Programa PODER, específicamente del componente Solidaridad y Convivencia Escolar. El propósito fundamental de establecer un sistema de monitoreo en las instituciones educativas del país era generar un medio de producción de información estadística sobre los casos de violencia escolar suscitados dentro de la escuela; todo ello se intentaba alcanzar mediante una línea de base que facilitara el diseño de indicadores pertinentes al fenómeno en cuestión, del cual se derivaran acciones preventivas elaboradas y ejecutadas por todos los integrantes de la comunidad educativa. Dicho ejercicio de monitoreo pretendía ser periódico, de tal manera que cada 6 meses del año se obtuvieran datos que demostraran la situación de violencia dentro de los centros educativos.

E1 documento denominado Sistema de Monitoreo de Violencia Escolar fue publicado por el MINED en el año 2007 y constituyó el material bibliográfico de referencia durante la Campaña contra la Violencia de Género del MINED llevada a cabo en 53 centros escolares en donde existía una necesidad tangible de crear mejores espacios de convivencia entre los estudiantes. El sistema de monitoreo formó parte de una serie de documentos vinculados a la Política Nacional de la Mujer, promovida por el Gobierno de ese entonces, que buscaba reducir las brechas de falta de equidad de género, para favorecer un sistema educativo con igualdad de oportunidades. La serie de documentos antes mencionada comprendía 5 tomos y una agenda de bolsillo donde se ilustraba el marco legal de protección contra la violencia, con ayuda de metodologías didácticas sencillas y acorde a la edad de los estudiantes. Los documentos de dicha serie son estos: 


\section{Figura 1}

\section{Estructura central del Sistema de Monitoreo de Violencia Escolar (SMVE):}
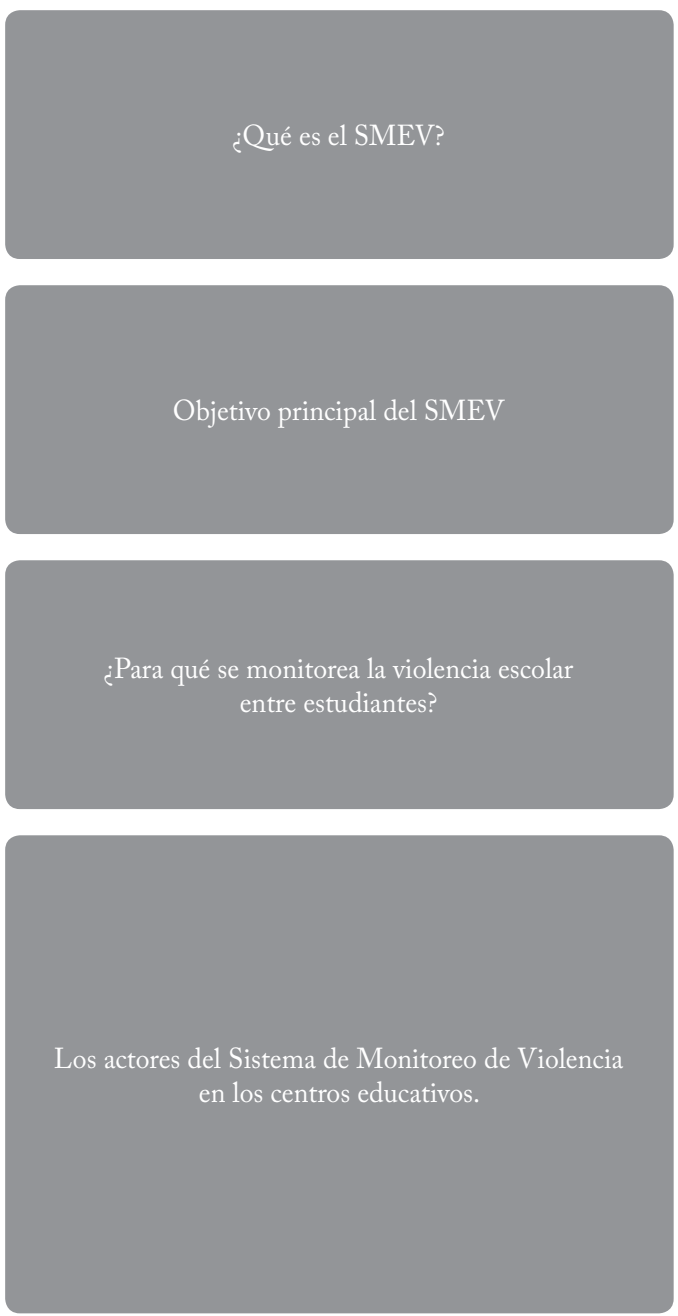

El SMVE es un conjunto de acciones previamente planificadas cuyo fin es documentar la situación de violencia entre estudiantes, para ejecutar un monitoreo de información que registre en forma sistemática los hechos de violencia más frecuentes que se susciten dentro del centro educativo.

Lograr que el SMVE se constituya en un mecanismo permanente de vigilancia escolar entre iguales en el ámbito escolar, a fin de medir periódicamente situaciones críticas, avances o retrocesos de la violencia entre educandos.

El SMVE busca rastrear a lo largo del tiempo un conjunto de acciones previamente planificadas cuyo fin es documentar la situación de violencia entre estudiantes, para ejecutar un monitoreo de información que registre en forma sistemática los hechos de violencia más frecuentes que se susciten dentro del centro educativo.

Existen 2 ámbitos en los cuales surgen los principales actores del SMVE, por un lado está el nivel de centro educativo, por otro el nivel local, dichos niveles se detallan a continuación:

Nivel de centro educativo: está conformado por estudiantes, docentes y padres y madres de familia.

Nivel local: este incluye a la comunidad (ADESCOS, gremios, comités comunitarios, Fiscalía General de la República, municipalidad, Policía Nacional Civil, Tribunales de Paz y de Familia, y Servicios de Salud).

Fuente: Sistema de Monitoreo de la Violencia Escolar MINED, 2007.

- Sistema de monitoreo de la violencia escolar.

- Guía metodológica de prevención de violencia de género para maestros.

- Guía educativa para la prevención de violencia de género para maestros.

- Guía educativa para la prevención de violencia de género para jóvenes.
- Guía metodológica para la prevención de la violencia de género para jóvenes.

- Agenda de bolsillo para la prevención de la violencia de género.

Dentro del análisis que compete al documento Sistema de Monitoreo de Violencia Escolar se 
puede argumentar que el MINED pretendía que dicho sistema se transformara en una actividad de planificación escolar, en donde el cuerpo docente y autoridades educativas tuviesen un control numérico de los casos reportados de violencia escolar, por medio de un diseño muestral que se apoyaría en una diversidad de herramientas de levantamiento de información.

A continuación se presenta la estructuración de contenido vertido en el Sistema de Monitoreo de Violencia Escolar (Ver Cuadro 1):

Véase a continuación una breve descripción de los puntos más relevantes (SMVE):

\section{A) Puntualización del problema de violencia} escolar: En este apartado del SMVE se argumenta que las conductas agresivas derivadas de proceso de socialización entre estudiantes no se limita a la mera agresión física, ya que se extiende a determinados abusos de poder en donde un grupo de estudiantes busca anteponerse sobre otros en una determinada colectividad escolar. Para el caso concreto de la puntualización de la violencia escolar, se percibe que los brotes de violencia y agresividad en las conductas estudiantiles son el mero resultado de lo aprendido en el hogar y lo que ocurre en la sociedad.

Para el SMVE destacan como fuentes de violencia escolar los elementos que se mencionan en el cuadro 2 .

B) Tipos de violencia en los centros educativos: Las argumentaciones que dan sustento al planteamiento del MINED en cuanto a la tipología existente sobre la violencia escolar, ponen al relieve del análisis, que durante los últimos tiempos se ha logrado percibir un aumento de conductas hostiles y destructivas en el comportamiento de algunos estudiantes; por lo tanto, si la sociedad está inmersa en un contexto violento y la escuela no es exenta de ello, no es nada extraño ver que en el interior de las escuelas se percibe en la conducta de los estudiantes una diversidad de manifestaciones que denotan violencia y peligrosidad.

La categorización del MINED en cuanto a la taxonomía de las conductas violentas se evidencia en el cuadro 3.

C) Propuesta para encausar la convivencia en los centros educativos: El SMVE propuesto por el MINED durante el año 2007 dejaba claro que las causas de violencia en las instituciones educativas eran multicausales, por lo que se requería de la participación activa de todos los miembros de la comunidad educativa para iniciar un proceso de desconstrucción de la violencia, en la que se volvía necesario experimentar cercanía y solidaridad como sentimientos contrapuestos a la rivalidad y a la intolerancia. Para el MINED, el SMVE respondía al propósito principal de dotar de un instrumento al cuerpo docente, en el cual se posibilitara la medición de situaciones de violencia en cualquiera de sus manifestaciones en el centro educativo, del que se pudieran obtener resultados periódicos que facilitaran la obtención de un análisis real de la situación de violencia entre escolares (Ver Cuadro 4). 


\section{Cuadro 1}

Estructura de contenido del Sistema de Monitoreo de Violencia Escolar MINED

\begin{tabular}{ll}
\hline 1. ${ }^{a}$ Parte & Puntualización del problema de violencia escolar \\
\hline 2. ${ }^{a}$ Parte & Tipos de violencia escolar \\
\hline 3. ${ }^{a}$ Parte & Descripción de propuestas de convivencia escolar \\
\hline 4. ${ }^{a}$ Parte & Indicadores y señales de advertencia de violencia en los centros educativos \\
\hline 5. ${ }^{a}$ Parte & Pautas metodológicas para muestras aleatorias estratificadas proporcionales \\
\hline $6 .{ }^{a}$ Parte & Propuesta de instrumentos o encuestas \\
\hline 7. ${ }^{a}$ Parte & Pautas metodológicas para el procesamiento manual de información \\
\hline 8. ${ }^{a}$ Parte & Criterios generales para el diseño de una línea de base \\
\hline 9. ${ }^{a}$ Parte & Pautas para analizar resultados o hallazgos \\
\hline 10. ${ }^{a}$ Parte & Criterios de planificación de acciones de prevención de violencia en el C.E. \\
\hline
\end{tabular}

Fuente: Sistema de Monitoreo de Violencia Escolar; Ministerio de Educación de El Salvador MINED, 2.a Edición, 2008. Págs. 4 y 5, San Salvador, El Salvador.

\section{Cuadro 2}

Fuentes de la violencia escolar según el SMVE-MINED

\begin{tabular}{|c|c|}
\hline $\begin{array}{l}\text { A nivel de la } \\
\text { sociedad y del } \\
\text { medio ambiente }\end{array}$ & $\begin{array}{l}\text { - Desigualdades sociales entre sectores afectados por la pobreza. } \\
\text { - Influencia de los medios de comunicación en escolares. } \\
\text { - Culturización de la violencia en los centros escolares. } \\
\text { - Facilidad para consumir alcohol y drogas por parte de estudiantes. }\end{array}$ \\
\hline $\begin{array}{l}\text { En el plano de } \\
\text { las relaciones } \\
\text { interpersonales }\end{array}$ & $\begin{array}{l}\text { - Escasa formación docente en el tema. } \\
\text { - Desmotivación del estudiante ante la falta de metodologías atractivas. } \\
\text { El empobrecimiento de la comunicación y el aumento de relaciones presididas } \\
\text { por la rivalidad, el individualismo y el debilitamiento del sentido de comunidad. }\end{array}$ \\
\hline $\begin{array}{l}\text { En el ámbito } \\
\text { de la institución } \\
\text { escolar }\end{array}$ & $\begin{array}{l}\text { - Múltiples exigencias de adaptación provenientes de un entorno escolar no } \\
\text { apropiado. } \\
\text { - Grupos de escolares numerosos que impiden una atención educativa más } \\
\text { personalizada. }\end{array}$ \\
\hline $\begin{array}{l}\text { Lo que se refiere } \\
\text { a la familia }\end{array}$ & $\begin{array}{l}\text { - Desintegración del grupo familiar. } \\
\text { - Familias monoparentales debido al insuficiente entramado socioeconómico de la } \\
\text { familia, derivándose con ello una subcultura delictiva. }\end{array}$ \\
\hline $\begin{array}{l}\text { En cuanto a la } \\
\text { personalidad }\end{array}$ & $\begin{array}{l}\text { - Desorientación axiológica. } \\
\text { - Legitimización del uso de la violencia para alcanzar sus propias metas. } \\
\text { - Métodos pedagógicos basados en malas comparaciones y en castigos. } \\
\text { - Asimetría en las relaciones sociales y de comunicación entre los miembros de } \\
\text { la comunidad docente. } \\
\text { - Utilización de la violencia en el hogar como método de resolución de problemas. }\end{array}$ \\
\hline
\end{tabular}

Fuente: Sistema de Monitoreo de la Violencia Escolar MINED, 2007. 


\section{Cuadro 3}

Tipos de violencia en los centros educativos

\section{Interrupción en las aulas}

Acciones de baja intensidad que interrumpe el ritmo de las clases, impidiendo con ello la labor educativa. (Problemas de indisciplina en gran escala)
Indisciplina/conflictos entre profesorado y alumnado

Manifestación de problemas de indisciplina que causan desorden debido a la falta de reconocimiento de autoridad del docente por parte del estudiante, en el cual se evidencia el desafío, la amenaza y la agresión.

\section{Vandalismo y daños materiales \\ Los estudiantes buscan crear una expresividad destructiva por medio de conductas violentas que buscan reclamar la atención del docente y de las autoridades escolares.}

\section{Violencia física}

Alarmante crecimiento de conatos de agresión física entre estudiantes, en donde predominan los episodios de violencia atentatoria contra el buen clima de convivencia escolar.

\section{E1 bullying}

Aparecimiento dentro de los climas de convivencia escolar, de procesos de intimidación y victimización entre estudiantes, provocando violencia física que deriva en el resquebrajamiento de la salud mental de la víctima.

\section{El acoso sexual}

Manifestación oculta de conductas antisociales de acoso sexual, que suelen desarrollarse de forma sistemática hasta constituirse en un delito.

Fuente: TORREGO, J.C. Mediación de conflictos en instituciones educativas; Madrid, Narcea. Págs. 5-7 Año 2000.

\section{Cuadro 4}

Planteamiento concreto de la propuesta del MINED vertida en el Sistema de Monitoreo de Violencia Escolar

E1 Sistema de Monitoreo de Violencia Escolar articula en su estructura los siguientes momentos:

1. El establecimiento de indicadores de medición de violencia.

2. Definición de la muestra.

3. Elaborar el instrumento o cuestionario.

4. Sistematización o tabulación de los resultados.

5. Análisis de los resultados.

6. Planificación de acciones de prevención, sanción y erradicación.

Fuente: Sistema de Monitoreo de la Violencia Escolar MINED, 2007. 
3.1. MINED y la adopción de posturas institucionales ante la violencia escolar salvadoreña

Como parte del reconocimiento de la grave problemática que constituye la violencia escolar para las autoridades educativas de El Salvador y el rápido crecimiento de dicho fenómeno, durante el mes de marzo del año 2009, el entonces viceministro de educación el doctor Eduardo Badía Serra, elaboro para todo el conglomerado docente del país la circular \# 07-2010, en la que el funcionario de Gobierno argumentaba sobre el problema lo siguiente: "Ante los incrementos de casos de violencia escolar acontecidos en el país en el presente año, el Ministerio de Educación requiere que, al interior de los Centros Educativos, se implementen las medidas necesarias que permitan prevenir acciones de violencia en contra del estudiantado. Las propuestas que a continuación se presentan, están comprendidas en el Plan de Atención Integral de la población estudiantil, donde el resto de la comunidad educativa evidencie altos niveles de compromiso". ${ }^{10}$

En dicha circular se giraban instrucciones para que las autoridades de cada centro escolar, con el apoyo del consejo de profesores, consejo de estudiantes y los comités de padres y madres de familia, fueran convocados por el organismo de administración escolar para conformar una propuesta conjunta que permita que los estudiantes sepan cómo actuar durante la convivencia escolar, sobre todo en aquellos centros educativos con mayores niveles de violencia.

10 Circular 07-2010. “Orientaciones para la comunidad educativa sobre las acciones tendientes a la reducción de la violencia escolar"; Ministerio de Educación de El Salvador, MINED, firmada por el Dr. Eduardo Badía Serra; E1 Salvador, marzo de 2010.
Para efectos del argumento anterior, el Dr. Badía recomendaba lo siguiente: ${ }^{11}$

1. Aplicar los instrumentos de convivencia escolar vigentes: Plan de Protección Integral, Manuales de Convivencia, Normativa o Reglamento Interno de la Institución.

2. Abordar las normas básicas de prevención de violencia en tiempo de clases, creando espacios y momentos para la orientación de estudiantes.

3. Desarrollar una Escuela de Padres y Madres donde se aborden las acciones de prevención de violencia escolar contra estudiantes.

4. Conformar la Red de Apoyo Comunitario con padres y madres de familia, asi como con otros miembros relevantes de la comunidad.

5. Adelantar la celebración de los Juegos Intramuros, para que los y las estudiantes comiencen a tener espacios de recreación al interior del Centro Escolar.

6. Activar en los Centros Escolares, las diferentes agrupaciones de estudiantes, como las bandas de paz, grupos de danza, grupos de música andina, etc. Para que los estudiantes comiencen a disponer de espacios para la expresión artística; acciones que cuentan con el respaldo de la Gerencia de Programas Complementarios de la Dirección Nacional de educación.

A finales del 2011, el MINED elaboró bajo la coordinación del doctor Eduardo Badía Serra y el Consejo Nacional de Educación (CNE), la

11 Ibíd. 
convocatoria a la Primer Consulta Nacional de Educación para un País sin Violencia. El Consejo Nacional de Educación es un organismo adscrito al Ministerio de Educación creado mediante Acuerdo del Órgano Ejecutivo número $97 \mathrm{y}$ publicado en el Diario Oficial con fecha 9 de diciembre de 2009.

Entre sus atribuciones el CNE -instancia de carácter técnico y consultivo- tiene la potestad de abrir espacios, escuchar y tomar en consideración las opiniones de otras instituciones sociales. Para cumplir con esta misión, después de debatir ampliamente sobre la violencia que afecta a la comunidad educativa, el CNE decidió llevar a cabo una consulta nacional para conocer la opinión de todos los sectores sociales que de una $u$ otra forma tenían algún tipo de involucramiento con el tema de violencia escolar; al respecto, el Informe de sistematización y validación de los resultados de la Consulta Nacional Educación para un país sin violencia, del Instituto Universitario de Opinión Pública (IUDOP) de la Universidad Centroamericana José Simeón Cañas (UCA), presentado en diciembre de 2011, manifestaba lo siguiente:

Las condiciones de inseguridad que imperan en el pais han tenido un efecto negativo en la actividad educativa de gran parte de los centros escolares de la nación. Asimismo, la necesidad de lograr una educación más inclusiva y de calidad, vinculada estrechamente con la realidad y la comunidad, con mejores niveles de equidad, lleva a considerar al CNE, la posibilidad de contribuir con sugerencias y recomendaciones orientadas a responder a las demandas de la realidad educativa en el país. Tomando en cuenta la realidad de violencia que se experimenta en los centros educativos, especialmente del sector público y el impacto que la misma tiene en el sistema educativo en su conjunto, el CNE decidió realizar una consulta nacional sobre los retos educativos nacionales y las propuestas de soluciones para una educación sin violencia.

La Primera Consulta Nacional de Educación para un País sin Violencia se consolidó como una acción que contó con la participación de 10 grupos que fueron convocados por el CNE, a fin de construir y validar una posible contribución que buscara la generación de ideas para orientar al país en la ruta que permitiera responder en forma concertada e integral al fenómeno de la violencia e inseguridad que se vive en las instituciones educativas del país. Dichos sectores representativos de la vida nacional abordaron de manera crítica y reflexiva la situación de la seguridad en E1 Salvador, puntualizando sobre la violencia y las posibles soluciones que se pueden proponer para resolverla.

En esa consulta discutieron básicamente dos temas:

1. ¿Qué propuestas se pueden hacer a la nación para enfrentar el grave problema de la violencia en la escuela?

2. ¿Qué compromisos puede asumir el pueblo salvadoreño para que esta iniciativa (Primer Consulta Nacional de Educación para un País sin Violencia) pueda conducir paulatinamente a una sociedad que albergue escuela sin violencia?

La realización de esta Primera Consulta Nacional pretendía "rescatar los resultados obtenidos para elaborar y presentar a las 
instancias oficiales responsables de la seguridad de la población salvadoreña un documento que facilitara la consecución de un diagnóstico y propuestas de solución que permitieran cultivar, con responsabilidad ciudadana y perseverancia, los valores que conforman la Cultura de Paz."12

A continuación se presenta un resumen de lo expresado por los sectores consultados, con el objeto de que sirviera de referencia para la ruta a seguir en la construcción futura de soluciones a la realidad de inseguridad que se vive en las instituciones educativas del país, tomando como base dos elementos clave utilizados durante el ejercicio: el diálogo y la búsqueda de consensos.

Los elementos que se expresaron como puntos de consenso por los sectores consultados, pueden verse en el cuadro 5 .

\subsection{La seguridad en las escuelas: propuesta del MINED con medidas disuasivas contra el flagelo de la violencia escolar}

Con el firme propósito de eliminar los conflictos y rivalidades entre estudiantes en donde se generan riñas callejeras y otra serie de delitos que se contraponen con la sana convivencia escolar, el 1 de marzo del año 2010 los titulares de la Policía Nacional Civil (PNC), Carlos Antonio Ascencio, y del Ministerio de Educación (MINED), Salvador Sánchez Cerén, estamparon sus rúbricas en sendos convenios de entendimiento y cooperación para la prevención de la violencia

\footnotetext{
12 Ver nota de referencia en http://www.mined.gob.sv/index.php/ temas/atencion-a-estudiantes-con-desempeno-sobresalienteaeds/item $/ 5308$-educaci $\%$ C $3 \%$ A $3 \%$ C 2\%B 3 n-para-un-
} pa $\%$ C3\%A3\%C2\%ADs-sin-violencia.html estudiantil y brindar de esa forma protección a los conglomerados estudiantiles tanto en el interior como en el exterior de sus centros de estudios.

Las autoridades policiales de ese entonces, orientaron sus labores a brindar seguridad y protección a un aproximado de 750 centros educativos localizados en los municipios de San Salvador, San Marcos, San Martín, Soyapango, Ilopango, Apopa, Ciudad Delgado, Colón, Santa Tecla, Mejicanos, Ayutuxtepeque, Cuscatancingo, Tonacatepeque, Ahuachapán y Atiquizaya.

Al respecto, se menciona en una nota periodística lo siguiente: "Una de las medidas del convenio, será la presencia policial en el perímetro de los centros educativos, en algunos casos con alguna particularidad, buscando además que no se infiltre gente ajena a la comunidad educativa con el propósito de cometer algún hecho delictivo o de inducir a incorporarse a pandillas.” No obstante de que con estas medidas se buscaba resguardar la seguridad perimetral de los centros educativos, la firma del convenio entre ambas instituciones se llevaría a cabo dentro de la ejecución del plan policial denominado Batalla por la Paz, en donde la PNC intentaba resguardar la integridad física de aquellos menores de edad que, estudiando en centros escolares, se encontraban en riesgo de sufrir trata, inducción a las drogas, reclutamiento en pandillas o ser víctimas de extorsión y de abuso. El apoyo que autoridades y Gobierno buscaban brindar a escolares, también incluía el hecho que los agentes estarían pendientes de que los estudiantes abordaran los buses y microbuses escolares sin ninguna dificultad, además se buscaba, por parte de los miembros de la institución policial, ofrecer a los estudiantes actividades ocupacionales enfocadas en 


\section{Cuadro 5}

Elementos que se expresaron como puntos de consenso por los sectores consultados

\begin{tabular}{|c|c|}
\hline Puntos de consenso & Análisis causal \\
\hline Maras y pandillas & $\begin{array}{l}\text { Las maras y pandillas operan dentro o fuera de los centros } \\
\text { educativos públicos, utilizando la violencia para coaccionar y } \\
\text { causar temor entre los estudiantes, docentes, directores, padres } \\
\text { de familia y demás miembros de la comunidad educativa. }\end{array}$ \\
\hline Medios de comunicación & $\begin{array}{l}\text { La transmisión de contenidos violentos y la elevada } \\
\text { cobertura o exposición de hechos de violencia en los medios } \\
\text { de comunicación, abona a la problemática de la violencia. }\end{array}$ \\
\hline Fundamentación axiológica & $\begin{array}{l}\text { Existe carencia de la promoción de valores morales y } \\
\text { espirituales, tanto en el hogar como en la escuela, la Iglesia } \\
\text { y la sociedad en general. }\end{array}$ \\
\hline Exclusión social & $\begin{array}{l}\text { La exclusión social, la desigualdad y la marginalidad } \\
\text { contribuyen a generar violencia. }\end{array}$ \\
\hline Deserción y ausentismo escolar & $\begin{array}{l}\text { La deserción, el ausentismo escolar, el descenso en la matrícula } \\
\text { y los traslados de profesores son consecuencias importantes } \\
\text { de la situación de violencia en el sistema educativo. }\end{array}$ \\
\hline $\begin{array}{l}\text { Acuerdos nacionales como } \\
\text { políticas de Estado }\end{array}$ & $\begin{array}{l}\text { Cualquier solución que se plantee debe pasar por una } \\
\text { coordinación interinstitucional y/o intersectorial funcional, } \\
\text { con el propósito de avanzar hacia un acuerdo nacional. }\end{array}$ \\
\hline $\begin{array}{l}\text { Diseño y fomento de } \\
\text { programas preventivos }\end{array}$ & $\begin{array}{l}\text { Se deben diseñar e impulsar programas preventivos } \\
\text { enfocados en talleres vocacionales, oportunidades laborales } \\
\text { y uso productivo del tiempo libre en los jóvenes. }\end{array}$ \\
\hline Calidad educativa & $\begin{array}{l}\text { La calidad educativa (tanto rendimiento escolar como el } \\
\text { ambiente) se ve seriamente afectada por el clima de miedo, } \\
\text { amenazas y violencia que predomina en las escuelas. }\end{array}$ \\
\hline Perspectiva política & $\begin{array}{l}\text { Los intereses político-partidarios han sido un obstáculo } \\
\text { para formular una política de Estado en el tema de violencia } \\
\text { y políticas públicas inclusivas que generen bienestar social. }\end{array}$ \\
\hline Contexto familiar & $\begin{array}{l}\text { El debilitamiento y la ruptura de la familia impiden que esta } \\
\text { cumpla con su papel de protección, orientación y provisión } \\
\text { de afecto. }\end{array}$ \\
\hline
\end{tabular}

Fuente: Consejo Nacional de Educación MINED; “Educación para un país sin violencia; manifiesto a la Nación” (en línea) Sitio oficial del Ministerio de Educación de El Salvador, 30 noviembre 2011, (fecha de consulta: 29 de septiembre de 2014) Disponible en http://www.mined.gob.sv/index.php/ints/item/5345-\%E2\%80\%9Ceducaci\%C3\%B3n-para-un-pa\%C3\%ADssin-violencia\%E2\%80\%9D-manifiesto-a-la-naci\%C3\%B3n.html 
aprovechar su tiempo; así mismo, que los agentes acompañaran en ciertos puntos a los educandos que se dirigían hacia sus casas caminando.

\section{Intervención de la Fuerza Armada de El Salvador en combate directo contra la violencia escolar}

Si el primero de marzo de 2010 las autoridades del MINED y PNC suscribían convenios de cooperación para resguardar los centros educativos del país, el 30 de enero de 2012 el MINED volvía a suscribir un nuevo compromiso de cooperación; pero en esta oportunidad lo haría con la Fuerza Armada de E1 Salvador. Este nuevo convenio se creaba con el fin de prevenir hechos de violencia en el campo educativo, por lo que el entonces ministro de Educación, Salvador Sánchez Cerén, y las autoridades de seguridad firmaron un plan interinstitucional de prevención y protección escolar, el cual se denominó Plan Escuelas Seguras. Al respecto el ministro de Justicia y Seguridad Pública, David Munguía Payés señalaba lo siguiente:

Nos sentimos honrados de participar en estas acciones de atención a estudiantes por lo cual nos acogemos a los acuerdos de cooperación con el MINED para llevar un mayor aprovechamiento de los recursos y para una mayor eficacia de la actuación de nuestra corporación. ${ }^{13}$

El acompañamiento de una perspectiva académica en el establecimiento de una escuela segura en el contexto educativo, permite retomar

13 FLORES, Gloria; MINED, PNC y Seguridad suscriben plan de protección escolar (en línea) Edición digital La Prensa Gráfica, 30 de enero de 2012, (fecha de consulta 6 de julio de 2015) disponible en http://www.laprensagrafica.com/el-salvador/social/246170-minedpnc-y-seguridad-suscriben-plan-de-proteccion-escolar.html a la connotada pedagoga canadiense Rebekka Maryan Sybile, quien se desempeña como asesora y docente formadora de la Universidad de Queensland Canadá, y manifiesta que una escuela segura y preocupada toma como referente los siguientes argumentos:

Una escuela segura es aquella que tiene la facilidad de proponer la creación de un entorno adecuado para ejercer idóneos procesos de enseñanza y aprendizaje, en el cual se busque en todo momento garantizar la implementación de una buena educación y la seguridad integral de los niños. La escuela segura, posee una estructura sostenida en sus principios y valores, los cuales encarnan vida en la propia comunidad educativa quien se empodera de un liderazgo propositivo en el cual se consolidan climas armoniosos de convivencia y ambientes seguros, en el cual los conglomerados estudiantiles estén conscientes y preparados para afrontar los riesgos que se desprenden de las situaciones de violencia e inseguridad existentes. ${ }^{14}$

Bajo el argumento interpretativo de la doctora Sybile, una escuela segura es aquella que valora la condición ambiental del entorno y profundiza la importancia de los mecanismos de socialización sobre los cuales se construye el día a día en el aula. Ante ello el convenio firmado por el MINED y la Fuerza Armada de El Salvador (Escuela Segura) se centraba en la unificación de esfuerzos para reducir los factores de riesgo que afectan a la comunidad educativa, sobre todo en entornos violentos, donde la escuela experimenta interrupciones por dichas acciones;

14 MIRANDA LENDETA, Julia Estebana. Mejorando el clima del aula por medio de la cultura de la mediación e intervención; Editorial Redes Literarios, Medellín Colombia, págs. 57-60, Año 2004. 
pero el docente continúa su empeño por ofrecer un entorno pacífico y mentalmente saludable para el aprendizaje de los educandos.

Durante el año 2011 el titular del Ministerio de Educación (MINED) argumentaba que se lanzarían estrategias y medidas para lograr un verdadero escudo de protección para estudiantes. $\mathrm{Su}$ posicionamiento partía de la idea de que se desarrollarían planes a través de programas específicos, en los que se incluían talleres de arte, clubes deportivos, actividades de esparcimiento y culturales, entre otros. Por el lado de la Fuerza Armada, su punto de vista referido al denominado Plan Escuelas Seguras, establecía marcos de cooperación en los que se buscaba evitar los homicidios en el sector estudiantil, buscando además que, como representantes de la autoridad, no defraudarían en su intento por brindar la seguridad tan añorada en las instituciones escolares. El plan de prevención y protección escolar fue suscrito entre la Policía Nacional Civil, el MINED y el Ministerio de Justicia y Seguridad Pública, a través de la Dirección General de Prevención Social de la Violencia y Cultura de Paz (PREPAZ). El objetivo de esta iniciativa fue unificar esfuerzos para gestionar y ejecutar acciones de prevención, protección y formación integral de los estudiantes, a fin de minimizar los elementos de riesgo que provocan violencia en la comunidad educativa.

\subsection{Cambio de ruta en los planes de seguridad escolar}

A finales del mes de septiembre del año 2013 la estrategia gubernamental Plan Escuela Segura fue radicalmente modificada por las autoridades del ramo educativo y se cambió por la nueva estrategia denominada Plan de Prevención y Seguridad Escolar. Esa estrategia buscaba integrar a varias entidades públicas para erradicar la violencia. El desarrollo de la nueva estrategia se basaba en focalizar los centros educativos ubicados en las zonas del país, con un mayor riesgo, en donde ya no intervendría solamente el MINED y la PNC, puesto que con la nueva reestructuración se incorporó a la lucha contra la violencia en las escuelas, instancias como la Fiscalía General de la República, el Ministerio de Gobernación, las alcaldías, entre otras. Al respecto el viceministro de Educación, Héctor Samour, argumentaba:

"Los cambios de planes en el abordaje a la violencia escolar, se deben a que la estrategia anterior (Plan Escuelas Seguras) no fue muy eficiente en el combate de la delincuencia que afecta a las escuelas, principalmente motivada por pandilleros; el plan funcionó, pero dio resultados muy limitados debido a que el fenómeno es más complejo". 15

La nueva dirección que tomaban las estrategias gubernamentales para el combate a la violencia escolar permitió que en el marco de la presentación de los nuevos planes y programas, se señalaran los principales 12 problemas que enfrenta la comunidad educativa, aunque la edición de La Prensa Gráfica del 25 de septiembre de 2013, fuente donde se destacaba la información antes mencionada, no dice de forma clara y precisa si estos 12 problemas

15 FLORES, Ricardo; MINED reconoce pocos resultados en plan escolar (en línea) Edición digital La Prensa Gráfica, 25 de septiembre de 2013 (fecha de consulta: 8 de julio de 2015) disponible en http:// www.laprensagrafica.com/2013/09/25/mined-reconoce-pocosresultados-en-plan-escolar 
son los causantes del cambio del Plan Escuela Segura por el Plan de Prevención y Seguridad Escolar y daba un margen de particular interpretación al momento de justificar cambios en el abordaje y el tratamiento a la violencia en el sistema educativo salvadoreño.

Los 12 problemas señalados se describen en el cuadro 6.

\subsection{Plan de Prevención y Seguridad Escolar, la nueva propuesta del MINED}

A menos de 60 días para finalizar el año escolar 2013, la Comisión Interinstitucional e Intergremial del Sector Docente presentó una nueva apuesta estratégica a la lucha contra el creciente fenómeno de la violencia escolar, la cual se denominó Plan de Prevención y Seguridad Escolar 2013-2014. En esa propuesta se proponía dar mayor impulso de participación a todos los sectores de la sociedad involucrados en la prevención de la violencia escolar. La propuesta buscaba además contribuir a la construcción de un mejor entorno de seguridad en la escuela, así como también la fundamentación de una cultura de convivencia en el centro educativo. La comisión creadora del Plan de Prevención y Seguridad Escolar 2013-2014 era dirigida por el MINED, pero en esta ocasión ya no participaría solamente la PNC y la Fuerza Armada, si no que se incorporaban también los ministerios de Gobernación y Justicia y Seguridad Pública, Fiscalía General de la República y gremios magisteriales como Andes 21 de Junio, SIANDES, bases magisteriales, SITADMES 21 de junio, el Comité Pro Retiro Digno, SEDESA-BM y CODINES.
Al respecto el viceministro de Educación de la época, Héctor Samour, señalaba la importancia de articular esfuerzos y afirmaba lo siguiente: “El propósito es contribuir conjuntamente al establecimiento de una cultura de convivencia justa, pacífica e inclusiva, no solo en las escuelas, sino también en el seno de las familias y la comunidad". ${ }^{16}$

Desde el análisis de contenido de la nueva estrategia, el Plan de Prevención y Protección Escolar se dividió en dos ejes principales:

1. El primero se enfocaba en la prevención de la violencia bajo la responsabilidad del MINED.

2. El segundo es el combate de la violencia en el entorno escolar, que le corresponde a las autoridades de seguridad.

Para el caso particular de este plan, eran los ministerios de Educación, Justicia y Seguridad Pública y de Gobernación, los responsables de asumir la conducción estratégica, garantizando que todas las estructuras articuladas en torno a él se integraran a la ejecución del mismo en el territorio.

Al respecto, la nota del periódico digital La Página del 26 de septiembre de 2013 manifestaban que:

Esta estrategia logra abarcar a 345 centros educativos, a través de sus respectivos Organismos de Administración Escolar en

16 Noticias ciudadano MINED, Plan de prevención y seguridad escolar (en línea) Pagina web Ministerio de Educación de El Salvador, 25 de septiembre de 2013 (fecha de consulta: 9 de julio de 2015) disponible en https://www.mined.gob.sv/index.php/ints/item/6562plan-de-prevenci\%C3\%B3n-y-seguridad-escolar.html 


\section{Cuadro 6}

Doce principales problemas que enfrenta la comunidad educativa

\begin{tabular}{c|l}
\hline Problema señalado & \multicolumn{1}{c}{ Argumentación que lo justifica } \\
\hline Falta de liderazgo & $\begin{array}{l}\text { Algunos directores de escuelas no ejercen su función en la organización de } \\
\text { las estructuras escolares. }\end{array}$ \\
\hline Descoordinación & $\begin{array}{l}\text { Falta coordinación institucional e intersectorial en las instancias locales } \\
\text { sobre violencia social en escuelas. }\end{array}$ \\
\hline Desconocimiento & Hay centros escolares donde docentes desconocen la normativa legal del país. \\
\hline Conflicto & $\begin{array}{l}\text { Las autoridades encontraron que en algunas escuelas hay conflictos entre } \\
\text { los miembros de la comunidad educativa. }\end{array}$ \\
\hline Inseguridad & $\begin{array}{l}\text { Muchos docentes y alumnos sufren acoso por parte de pandilleros u otros } \\
\text { grupos delincuenciales externos a las escuelas. Hay un ambiente inseguro } \\
\text { tanto dentro como fuera. }\end{array}$ \\
\hline Dispersión & No hay un esfuerzo coordinado para prevenir la violencia escolar. \\
\hline Desinterés & $\begin{array}{l}\text { Hay sitios donde las familias no están interesadas en involucrarse en la } \\
\text { educación de los hijos. }\end{array}$ \\
\hline Sin talleres & Faltan oportunidades para la utilización efectiva del tiempo de vacaciones. \\
\hline Hay pocos talleres vocacionales en marcha.
\end{tabular}

Fuente: Elaboración propia a partir de nota en La Prensa Gráfica del 25 de septiembre de 2013.

donde se incorpora además a 121 Concejos

Municipales para la prevención de la violencia. La implementación se hace a nivel departamental por medio de 14 Gabinetes

de Gestión, 14 Consejos Consultivos de Educación, 120 Consejos Consultivos de Educación (municipales), 345 Consejos
Consultivos de Educación (comunales) y otras organizaciones. ${ }^{17}$

17 HERNÁNDEZ, Carlos; Autoridades de Educación y Seguridad crean plan para prevención y combate de violencia (en línea) Edición digital Periódico La Página, 26 de septiembre de 2013 (fecha de consulta: 9 de julio de 2015) disponible en http://www.lapagina. com.sv/nacionales/87375/2013/09/26/Autoridades-de-educacion-yseguridad-crean-plan-para-prevencion-y-combate-de-violencia 
La organización de dicho Plan de intervención a la violencia escolar, contaba con metas estratégicamente proyectadas entre las cuales están:

A. Realización de campañas educativas para la sensibilización y divulgación de procesos de prevención de la violencia escolar con un enfoque de corresponsabilidad.

B. Creación de mecanismos de comunicación efectiva y empática entre los actores involucrados en el plan.

C. Capacitar en temas de convivencia escolar y cultura de paz al 100\% de los actores a nivel local y distrital de los centros educativos focalizados.

D. Desarrollar 14 foros departamentales sobre el tema de construcción de paz desde los centros educativos y 2 diplomados de prevención de la violencia escolar para equipos docentes.

\section{La estrategia de movilización nacional por} la vida, la paz y la justicia, como mecanismo vinculante en la cultura de paz escolar 2015

El Ministerio de Educación de El Salvador, como parte de la búsqueda de soluciones a la grave problemática de la violencia escolar, decidió emprender un acompañamiento a la iniciativa del Consejo Nacional de Seguridad y Convivencia Ciudadana. Este acompañamiento se desarrolla en el marco de una movilización nacional que permita que los estudiantes, como involucrados directos en acciones de violencia, puedan promover el respeto a la vida, la paz, la justicia y fomentar la convivencia social en el país, de manera particular en los centros educativos.
Fue así como el 18 de marzo de 2015 el MINED, bajo la dirección del ministro Carlos Mauricio Canjura Linares, emite la circular \# 3-2015, en la cual se les solicita a los docentes coordinarse con las direcciones departamentales a fin de apoyar e incorporarse a las diversas actividades que pueda llevar a cabo el Consejo Nacional de Seguridad y Convivencia Ciudadana. El Ministro de Educación hace un reconocimiento de que la violencia es un fenómeno que afecta a todos los miembros de la comunidad educativa, por lo que invita a toda la ciudadanía a interiorizar valores de convivencia ciudadana en el diario vivir.

Partiendo del involucramiento directo de las autoridades educativas salvadoreñas en actividades que ayuden a combatir el flagelo de la violencia escolar, se puede argumentar que debido al alarmante crecimiento de dicho fenómeno, este se ha convertido en un tema que hoy despierta mucha sensibilidad social y genera múltiples inquietudes. Si bien es cierto que la violencia en la escuela salvadoreña no es reciente, es de destacar que la violencia ha evolucionado de forma tal que esta se transforma en un hecho de criminalidad en el que se transgrede la ley hasta llegar a casos de homicidios adentro como afuera de los recintos escolares. Al respecto, Jorge Manuel Esperanza Mayorga quien es el director del Instituto Salvadoreño para el Desarrollo Educativo, advertía que:

Por muchos años la violencia escolar en la sociedad salvadoreña permaneció oculta y en silencio al dañar no solo a los afectados, sino a toda la comunidad educativa. Hoy en día la gran difusión de información en torno al tema lo ha convertido en un asunto prioritario en las agendas de las escuelas y en una preocupación 
recurrente para muchos padres y docentes. Sin embargo, es frecuente escuchar afirmaciones erróneas en torno al tema, muchas de las cuales reciben poco o ningún apoyo cuando se trata de contrastarlas con los datos empíricos, esto debido a que el MINED no cuenta con datos sistematizados en el tema de violencia escolar, generando con ello falsos argumentos que señalan que la violencia en las instituciones educativas, es un problema de la escuela y no de la convulsión social por la que atraviesa el país. ${ }^{18}$

Siempre en la línea del análisis emanado por el MINED, en la circular antes mencionada, el ministro Canjura emitió una serie de acciones para el fomento de la vida, la paz y la justicia, bajo el enfoque de competencias académicas y sociales promovidas por el personal docente para el estudiantado; entre las competencias académicas sugeridas por el ministro de Educación están las siguientes:

1. Los docentes deberán promover prácticas de convivencia al interior de los centros educativos.

2. Todos los educadores deben identificar los contenidos académicos de los programas formativos que impulsen actitudes, valores y habilidades sociales para su promoción pedagógica, en donde se cree desde el interior de la institución educativa, un entorno escolar de protección, afecto y seguridad.

3. Las autoridades educativas en cada escuela, deberán implementar el Lunes Cívico, como

18 ESPERANZA MAYORGA, Jorge Manuel; "Manual de Escuelas de Padres y Educación Familiar”, Ediciones Pedagógicas Vicentinas, El Salvador, 2013. Pág. 17. el espacio propicio para realizar acciones pedagógicas que promuevan los valores de la vida, la paz y la justicia. Se sugiere además que mediante el arte, la recreación, la cultura y el deporte, se desarrollen actividades preventivas y de concientización sobre la violencia.

4. Los miembros de la comunidad educativa deberán identificar a los estudiantes necesitados de "primeros auxilios psicológicos" y gestionar el debido apoyo a las instituciones encargadas en brindar dichos servicios. ${ }^{19}$

A manera concluyente se puede interpretar que toda esta iniciativa de acompañamiento por parte del MINED a generar acciones concretas para afrontar la violencia que ataca día a día a las instituciones educativas, busca lanzar a un grito de auxilio en favor de la paz, logrando que en el interior de todas las instituciones educativas del país predomine un ambiente de armonía en la convivencia escolar; las autoridades educativas intentan marcar un accionar trascendental que despierte la esperanza y motive a toda la comunidad educativa a erradicar toda acción de violencia para construir un país justo, seguro e inclusivo.

\section{Conclusiones}

Como argumento final sobre este recorrido histórico en el que se aborda la evolución de la violencia escolar, y las diversas estrategias de intervención que se han implementado para su

19 Circular 03-2015 "Movilización Nacional por la Vida, la Paz y la Justicia"; Acciones sugeridas para el fomento de la vida, la paz y la justicia: Desarrollo de competencia académicas y sociales; Ministerio de Educación de El Salvador, MINED, firmada por el Dr. Carlos Mauricio Canjura Linares; El Salvador, marzo de 2015. 
abordaje y seguimiento en el sistema educativo salvadoreño, se puede concluir que desde la década de los 40's hasta la contemporaneidad pedagógica postmodernista, siempre han existido muestras de agresión y acoso escolar en el desarrollo de las relaciones sociales de las comunidades educativas en general. No obstante, en los últimos 10 años, el aparato educativo institucional ha percibido una involución en la cual se pasa de la violencia a la criminalidad en el interior del centro educativo, por lo que el estudio de la progresión del hecho histórico (violencia en el contexto educativo), ayuda a la comprensión de los antecedentes que han configurado una realidad pedagógica carente de análisis y propuestas efectivas en las que se pueda, de manera eficiente y efectiva, darle una solución a la agresión y el acoso escolar.

La presente reflexión histórica denota que se pasó de una rivalidad estudiantil a una criminalidad pandilleril,y que muy a pesar de las intervenciones de los cuerpos de seguridad no han logrado dar los resultados esperados; para muestra de la gravedad del asunto, durante el año 2004 se hablaba de 55 instituciones educativas con cobertura de programas de intervención en crisis, resolución de conflictos y disminución en el consumo de drogas (Plan de Gobierno País Seguro); para el año 2011 el Plan Escuelas Seguras del MINED aumentó la cobertura a 166 centros educativos quienes por la naturaleza de sus problemas de violencia contarían con el patrullaje de la PNC y militares; para septiembre de 2013 se modifica el Plan y se amplía a 346 centros educativos, para el mes de marzo de 2014 se extiende a 788 centros educativos y para el 2016 con el plan de prevención y seguridad escolar "Unidos por nuestras hijas e hijos” el número de escuelas aumentó a 1,063.
Todo lo anterior ha generado una densa neblina que impide ver a futuro alguna solución viable, por lo tanto es la intención de este aporte provocar en la comunidad educativa en general un interés por conocer la relevancia de los hechos históricos en educación y la comprensión de los mismos en su totalidad, ya que solamente conociendo los antecedentes de los fenómenos pedagógicos podremos pensar en una reestructuración de la escuela como institución promotora de la convivencia pacífica, hacedora de una cultura de paz y arquitecto de la construcción del nuevo tejido social que demanda nuestra nación.

\section{Fuentes consultadas}

BURGOS Ana / JOMA, Susana, "Proponen policía especial para la violencia escolar" (en línea) Edición digital El Diario de Hoy, 7 julio 2004 (fecha de consulta: 8 de julio de 2015) disponible en: http://www.elsalvador.com/ noticias/2004/07/07/nacional/nac3.asp\#

CASTRO SANTANDER, Alejandro. "Violencia silenciosa en la escuela. Dinámica del acoso escolar". Buenos Aires: Editorial Bonum, 2007.

ESPERANZA MAYORGA, Jorge Manuel; "Manual de escuelas de padres y educación familiar", Ediciones pedagógicas vicentinas, El Salvador, 2013, Pág. 17.

FLORES, Gloria, MINED, PNC y Seguridad suscriben plan de protección escolar (en línea) Edición digital La Prensa Gráfica, 30 de enero de 2012, (fecha de consulta: 6 de julio de 2015) disponible en: http://www.laprensagrafica. com/el-salvador/social/246170-mined-pnc- 
y-seguridad-suscriben-plan-de-proteccionescolar.html

FLORES, Ricardo, MINED reconoce pocos resultados en plan escolar (en línea) Edición digital La Prensa Gráfica, 25 de septiembre de 2013, (fecha de consulta: 8 de julio de 2015) disponible en: http://www.laprensagrafica. com/2013/09/25/mined-reconoce-pocosresultados-en-plan-escolar

HERNANDEZ, Carlos, Autoridades de educación y seguridad crean plan para prevención y combate de violencia (en línea) Edición digital Periódico La Página, 26 de septiembre de 2013, (fecha de consulta: 9 de julio de 2015) disponible en: http://www.lapagina.com.sv/ nacionales/87375/2013/09/26/Autoridadesde-educacion-y-seguridad-crean-plan-paraprevencion-y-combate-de-violencia

JOMA, Susana, Revisan "Escuela Segura" (en línea) Edición digital El Diario de Hoy, 9 de julio de 2004, (fecha de consulta: 7 de julio de 2015) disponible en: http://www.elsalvador. com/noticias/2004/07/09/nacional/nac2.asp

MINED, Circular 07-2010 Orientaciones para la comunidad educativa sobre las acciones tendientes a la reducción de la violencia escolar"; por el Dr. Eduardo Badía Serra; El Salvador, marzo 2010.

MINED, Circular 03-2015 "Movilización Nacional por la Vida, la Paz y la Justicia”; Acciones sugeridas para el fomento de la vida, la paz y la justicia: Desarrollo de competencia académicas y sociales; firmada por el Dr. Carlos Mauricio Canjura Linares; El Salvador, marzo 2015.
MINED; Consejo Nacional de Educación, "Educación para un país sin violencia; manifiesto a la Nación” (en línea) Sitio oficial del Ministerio de Educación de E1 Salvador, 30 de noviembre de 2011, (fecha de consulta: 29 de septiembre de 2014) disponible en:

http://www.mined.gob.sv/index.php/ints/ item $/ 5345-\% \mathrm{E} 2 \% 80 \% 9$ Ceducaci\%C3\%B3np a r a - u n - p a \% C $3 \%$ A D s - s i n violencia $\% \mathrm{E} 2 \% 80 \% 9 \mathrm{D}-\mathrm{manifiesto-a-1a-}$ naci\%C3\%B3n.html

MINED, "Memoria de labores Ministerio de Educación de El Salvador 2004-2005” Pág. 41

MINED, "Memoria de labores Ministerio de Educación de El Salvador 2006-2007” Pág. 14

MINED, Plan de prevención y seguridad escolar (en línea) Pagina Web Ministerio de Educación de E1 Salvador, 25 de septiembre de 2013, (fecha de consulta: 9 de julio de 2015) disponible en: https://www.mined.gob.sv/index.php/ints/ item/6562-plan-de-prevenci\%C3\%B3n-yseguridad-escolar.html

MINED, Primera consulta nacional de educación para un país sin violencia. Disponible en: http:// www.mined.gob.sv/index.php/temas/atencion-aestudiantes-con-desempeno-sobresaliente-aeds/ item/5308-educaci\%C3\%A3\%C2\%B3n-paraun-pa\%C3\%A3\%C2\%ADs-sin-violencia.html

MINED, Sistema de Monitoreo de Violencia Escolar, 2da Edición 2008 Págs. 4 y 5, San Salvador E1 Salvador.

PICARDO JOAO, Oscar Carlos, ¿Violencia en los institutos nacionales? (en línea) Edición 
digital La Prensa Gráfica, 30 de marzo de 2010, (fecha de consulta: 25 de septiembre de 2014) disponible en:

http://www.laprensagrafica.com/opinion/ editorial/104475-iviolencia-en-los-institutosnacionales

ROMERO, Fernando, PNC firma convenio de seguridad con MINED (en línea) Edición digital La Prensa Gráfica, 17 de mayo de 2010, (fecha de consulta: 4 de julio de 2015) disponible en: http://www.laprensagrafica.com/el-salvador/ social/97610-pnc-firma-convenio-seguridadcon-mined.html
ROMERO, Fernando, El origen de los encuentros violentos entre los estudiantes (en línea) Edición digital La Prensa Gráfica, 17 de mayo de 2010, (fecha de consulta: 1 de septiembre de 2014) disponible en: http://www. laprensagrafica.com/el-salvador/social/118165el-origende-los-encuentros-violentos-entre-losestudiantes.html

TORREGO, J.C. Mediación de conflictos en instituciones educativas; Madrid, Narcea Págs. 5-7 Año 2000. 